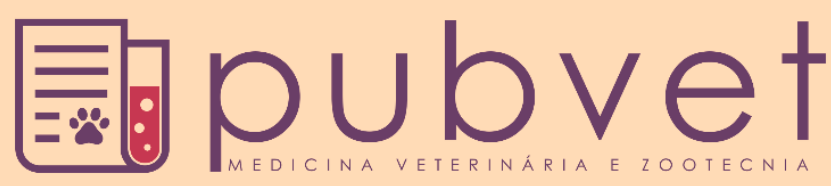

https://doi.org/10.31533/pubvet.v14n8a621.1-10

\title{
Formas de resistência microbiana e estratégias para minimizar sua ocorrência na terapia antimicrobiana: Revisão
}

\author{
Laura Gaspar Scaldaferri ${ }^{*} \bullet$, Emanuely Ramos Tameirão ${ }^{1 \bullet}$, Sibely Aiva Flores $^{1 \bullet}$, Rodrigo \\ Augusto Spaggiari Camargo Neves ${ }^{1}$, Thalita Santos Correia ${ }^{\circ}{ }^{\circ}$, Jéssica Roseane do Carmo $^{30}$, \\ Hugo Shisei Toma $^{4} \bullet$, Marcos Ferrante ${ }^{4}$
}

${ }^{I}$ Estudante de Medicina Veterinária pela Universidade Federal de Lavras. Lavras - MG.

${ }^{2}$ Estudante de Medicina Veterinária pela Faculdade Anísio Teixeira. Feira de Santana - BA.

${ }^{3}$ Estudante de Medicina Veterinária pela Universidade Federal de Juiz de For. Juiz de Fora - MG.

${ }^{4}$ Professor da Universidade Federal de Lavras, Departamento de Medicina Veterinária. Lavras - MG.

*Autor para correspondência, E-mail: laura.scaldaferri@estudante.ufla.br

Resumo. A resistência microbiana às terapias antimicrobianas tem sido um desafio histórico e permanente na saúde mundial. Diversas pesquisas buscam identificar as causas, assim como as formas de minimizar a ocorrência desta resistência. Este estudo foi realizado abrangendo artigos sobre saúde humana e veterinária, bem como discutindo as dificuldades acerca de sanar a problemática, apontando as causas das resistências e as principais estratégias para diminuir essas ocorrências. Nesse contexto, o uso indiscriminado de antibióticos em humanos e animais é tido como a principal causa do surgimento dessas resistências e a formação de superbactérias. A transferência de genes, a ocorrência de mutações e a formação de biofilmes são as formas que mais interferem na eficácia da terapia antimicrobiana. Conscientização da população quanto ao uso de antimicrobianos; Intensificar as pesquisas e o investimento na área, a fim de se produzir antimicrobianos mais adequados e específicos para determinado uso; Monitoramento da resistência visando mensurar o agravamento ou controle da mesma; Determinação de pontos epidemiológicos, objetivando a resolução dos mesmos; Adoção de medidas higiênico sanitárias, para diminuir os casos de infecção; Diminuição do uso de terapia empírica, diminuindo assim a utilização de antimicrobianos inadequadamente, ou por vezes, desnecessária são sugestões e estratégias para diminuir a ocorrência dessas resistências. Estratégias essas que vem sendo abordadas no Plano de Ação Global Contra a Resistência Antimicrobiana desde 2015.

Palavras chave: antibiótico, resistência, revisão, terapia antimicrobiana

\section{Forms of microbial resistance and strategies to minimize their occurrence in antimicrobial therapy: Review}

\footnotetext{
Abstract. Microbial resistance to antimicrobial therapies has been a historic and permanent challenge to the global health. Several researches seek to identify the causes, as well ways to minimize the occurrence of this resistance. In this study, a review of scientific articles related to the theme had carried out, covering human and veterinary health, as well as discussing the difficulties about solving the problematics, pointing out the causes of resistance and some strategies to reduce these occurrences. In this context, the indiscriminate use of antibiotics in humans and animals is seen as the main cause of the emergence of these resistances and the formation of superbugs. The gene transference, the occurrence of mutations and the formation of biofilms are the ways that interfere the most with the effectiveness of antimicrobial therapy. Public awareness regarding the use of antimicrobials; Intensify research and investment in the area, in order to produce more
} 
appropriate and specific antimicrobials for a particular use; Resistance monitoring aiming to measure its worsen or control; Determination of epidemiological points, aiming at their resolution; Adoption of hygienic sanitary measures to reduce cases of infection; Decreasing the use of empirical therapy, thus reducing the use of antimicrobials inappropriately, or sometimes, unnecessary are suggestions and strategies to reduce the occurrence of these resistances. Since 2015, these strategies have been addressed in the Global Action Plan On Antimicrobial Resistance.

Keywords: antibiotic, resistance, review, antimicrobial therapy

\section{Formas de resistencia microbiana y estrategias para minimizar su aparición en la terapia antimicrobiana: Revisión}

Resumen. La resistencia microbiana a las terapias antimicrobianas ha sido un desafío histórico y permanente en la salud global. Varios estudios buscan identificas las causas, así como formas de minimizar la aparición de esta resistencia. En este estudio, se lleva a cabo una revisión de artículos científicos relacionados con el tema, que cubren la salud humana y veterinaria, y se analizan las dificultades para resolver el problema, señalando las causas de la resistencia y algunas estrategias para reducir estos eventos. En este contexto, el uso indiscriminado de antibióticos en humanos y animales es visto como la principal causa de la aparición de estas resistencias y la formación de superbacterias. La transferencia de genes, la aparición de mutaciones y el biofilme son las formas que más interfieren con la efectividad de la terapia antimicrobiana. Conciencia pública sobre el uso de antimicrobianos más apropiados y específicos para un uso particular; Monitoreo de resistencia para medir su agravación o control; Determinación de puntos epidemiológicos, con el objetivo de su resolución; Adopción de medidas sanitarias higiénicas para reducir los casos de infección; Reducir el uso de la terapia empírica, disminuyendo así el uso de antimicrobianos de manera inapropiada, o en ocasiones innecesaria, son sugerencias y estrategias para reducir la aparición de estas resistencias. Desde 2015, estas estrategias se han abordado en el Plan de Acción Mundial contra la resistencia a los antimicrobianos.

Palabras clave: antibiótico, resistencia, revisión, terapia antimicrobiana

\section{Introdução}

Antibióticos são substâncias produzidas a partir de microrganismos ou sintéticos que podem atuar como bactericida, eliminando a bactéria ou bacteriostático retardando o seu crescimento e a sua multiplicação. O primeiro antibiótico descoberto foi a penicilina em 1928 por Alexander Fleming de maneira acidental, sendo utilizado clinicamente a partir de 1940, principalmente em pacientes na segunda guerra mundial, causando uma revolução no tratamento de muitas doenças em humanos e animais. Após esse período, novos antibióticos foram descobertos, como estreptomicina, tetraciclinas, cloranfenicol, neomicina, aminoglicosídeos tendo eles, além do uso para tratamento de doenças, também a utilização como promotores de crescimento animal. No entanto, entre 1976 e 1980 houve início relatos de resíduos de medicamentos nos tecidos de animais para alimentação, causando intoxicações em humanos (Caselani, 2014).

A aplicação indiscriminada de antibióticos em humanos e animais gerou o surgimento de microrganismos chamados de superbactérias, as quais são um grande problema atual para a saúde única. Bactérias desenvolveram mecanismos para sobrevivência no hospedeiro que podem ser explicadas pela seleção natural, dita por Charles Darwin, como transferência de genes, mutações e formação de biofilmes (Hopman et al., 2019). Assim, em 1961 apareceram os primeiros casos de resistência a penicilina, com o tempo a resistência a diferentes antibióticos foram surgindo. Atualmente, podemos considerar a era do uso racional de antimicrobianos, com intensa atividade para encontrar alternativas ao uso desses medicamentos (Prescott, 2017). 
Portanto, o objetivo dessa revisão é resumir tópicos atuais e importantes referentes à resistência antimicrobiana na medicina veterinária, e selecionar as principais estratégias para o controle desse problema no mundo atual.

\section{Formas de resistência que afetam a terapia antimicrobiana}

Para entender o problema da resistência bacteriana e desenvolver estratégias para reduzir o surgimento e a disseminação, é importante entender os mecanismos de como esses microrganismos se tornam resistentes. Bactérias apresentam uma grande capacidade de responder a ameaças ambientais, ao sistema imune do hospedeiro e à presença de antibióticos, por isso conseguem desenvolver diferentes formas de resistência para se adaptarem ao meio em que vivem o que acaba afetando negativamente a eficácia antimicrobiana em diversas terapias (Jolivet-Gougeon \& Bonnaure-Mallet, 2014),

Um dos principais fatores que favorecem o desenvolvimento de resistência bacteriana é a presença do antibiótico, relatado desde a década de 80 por McGowan Juniorr (1983) que pode levar a um desequilíbrio da flora bacteriana do paciente, favorecendo a proliferação de microrganismos oportunistas, contribuindo para o surgimento de novas infecções. Como diversos antibióticos fazem parte de uma mesma classe, quando um microrganismo desenvolve resistência a um medicamento, também acaba desenvolvendo a toda classe relacionada (Guardabassi et al., 2018; Guardabassi \& Prescott, 2015).

Alguns dos meios mais importantes para o desenvolvimento da resistência são através da transferência de genes de resistência entre bactérias ou a partir de mutações cromossômicas.

\section{Transferência de informação genética}

Por mecanismo de transferência de informação genética uma bactéria consegue obter um gene que vai lhe conferir resistência através de outra bactéria. Esse processo pode ser dividido em três formas: transformação, transdução e conjugação. A transformação é a forma mais simples, sendo quando a bactéria incorpora um gene de resistência presente no meio. Transdução é quando há passagem do gene entre duas bactérias através do bacteriófago, o que ocorre facilmente em Staphylococcus (Thomas \& Nielsen, 2005). Já a conjugação é a forma mais complexa que envolve a recombinação cromossômica célula a célula gerando novas misturas genéticas que serão transmitidas às células-filhas na divisão celular seguinte, esta forma ocorre principalmente em organismos Gram-negativos (Munita \& Arias, 2016).

\section{Mutação}

As mutações são as formas mais comuns de adquirir-se resistência. Elas podem alterar a ação do antibiótico pela produção de enzimas que vão inativar o antibiótico (Wilson, 2014), adição de moléculas que vão alterar a sua estrutura química, desenvolvimento de barreiras que impedem a entrada de antibiótico dentro da célula como, por exemplo, a resistência à vancomicina que não consegue penetrar a membrana plasmática de bactérias gram-negativas, modificações do alvo antimicrobiano, por exemplo, a resistência à meticilina em Staphylococcus aureus e ativação de bombas de efluxo, que são capazes de retirar a molécula de antibiótico de dentro da bactéria, impedindo sua ação no meio intracelular; mecanismo esse que afeta diversas classes de antibióticos, como as fluoroquinolonas, $\beta$ lactamas, carbapenêmicos e polimixinas (Ramirez \& Tolmasky, 2010).

\section{Biofilme}

Outra forma relevante de resistência é a formação de biofilme, como exemplo cotidiano da rotina clínica tem a formação de placas dentárias bacterianas, que tornam difícil a penetração de antibióticos. Pseudomonas spp e outras bactérias gram-negativas são grandes formadoras de biofilmes, tendo estas maiores capacidades de resistir ao sistema imune do hospedeiro e ao antimicrobiano, por isso, consideradas de complicada eliminação (Marsh, 2004). De acordo com Boothe (2006) a capacidade de resistência varia para cada microrganismo de acordo com classe e gênero. Por exemplo, muitos microrganismos ainda são previsivelmente suscetíveis aos antibióticos, como Brucella spp e Clamydia spp, enquanto outros desenvolvem rapidamente mecanismos de resistência contra até mesmo novos antibióticos como, por exemplo, E. coli, Klebsiella pneumoniae, Salmonella spp, Streptococcus pneumoniae e Staphylococcus aureus. Sendo, este último, o mais complicado entre os citados, pois são intrinsecamente virulentos, capazes 
de se adaptar a diversas circunstâncias ambientais, associados a infecções com elevado perigo de vida, tanto para os homens, quanto aos animais (Fluit \& Schmitz, 2004).

\section{Estratégias para diminuir a ocorrência de resistência}

Com objetivo de retardar o crescente aumento de resistência bacteriana, possibilitando assim, a continuidade de tratamentos, é importante estabelecer estratégias para otimizar o uso de antimicrobianos. Baseado no Plano de Ação Global, aprovado na Assembleia Mundial de Saúde em 2015 (WHO, 2015), envolvendo a coordenação entre vários setores internacionais, incluindo medicina humana e veterinária, agricultura, finanças, meio ambiente e consumidores, que tem por objetivo assegurar que a prevenção e o tratamento de doenças infecciosas com medicamentos seguros e eficazes continuem, podemos dividir as estratégias em alguns tópicos.

\section{Conscientização da população}

Estabelecer medidas para conscientizar a população a respeito da resistência antimicrobiana, pela promoção do ensino escolar, campanhas de conscientização, palestras educacionais, treinamentos e cursos para profissionais da área de saúde. Segundo Guardabassi \& Prescott (2015) uma educação adequada reduz o uso inadequado de antimicrobianos e aprimora o entendimento e a aceitação das estratégias de administração.

\section{Intensificação de pesquisas}

Intensificar o conhecimento a respeito de informações sobre os microrganismos resistentes, entendendo cada vez mais vez como desenvolvem mecanismos de resistência e a difusão entre as pessoas, os animais e o meio ambiente. Podendo ser feito por pesquisas, que envolve governos nacionais, organizações intergovernamentais, agências, organizações profissionais, organizações não governamentais, indústria e academia. Associado ao aumento de pesquisas é importante aumentar o investimento em novos medicamentos, ferramentas de diagnóstico, vacinas e outras intervenções No entanto, de acordo com o Plano de Ação Global para o Enfrentamento à Resistência aos Antimicrobianos, concebido pela OMS, muitas empresas interromperam os estudos, porque pesquisas e investimentos nessa área não são tão atrativos comparado a outros conteúdos (Estrela, 2018).

Apesar de estar avançando na medicina humana, estudos a respeito da otimização de doses ainda devem avançar na medicina veterinária, seguindo, por exemplo, Rairat et al. (2019) que estabeleceram um modelo farmacocinético-farmacodinâmico (PK-PD) para definir um regime ideal de dosagem antimicrobiana em peixes utilizando florfenicol, para isso, levou em consideração a farmacocinética dependente da temperatura e a suscetibilidade antimicrobiana do patógeno. Fernández-Varón et al. (2016) estabeleceram que o perfil sérico de concentração-tempo para o ceftiofur em cabras em lactação em diferentes formulações. Cao et al. (2015) avaliaram atividade antimicrobiana in vivo da marbofloxacina contra Pasteurella multocida, usando tecidos implantados subcutaneamente em bezerros, o que a partir de métodos de PK/PD in vivo do antibiótico mostraram a vantagem de avaliação da atividade antimicrobiana e da otimização do regime de dosagem de antibióticos na presença das defesas do hospedeiro, principalmente em animais alvo de interesse veterinário.

\section{Monitoramento de resistência:}

A forma de monitorar a AMR (resistência antimicrobiana) se deu por diferentes métodos em cada país envolvido no Plano de Ação Global de 2015, sendo realizadas adequações segundo condições tecnológicas e financeiras locais. Segundo o Plano de Ação Nacional de Prevenção e Controle da Resistencia aos Antimicrobianos no Ầmbito da Saúde Única (PAN-BR), publicado pelo Ministério da Saúde em 2018, o monitoramento da resistência no Brasil se dará a partir do estabelecimento de uma rede nacional de informação integrada para a vigilância e monitoramento da AMR no âmbito da saúde humana por meio de metodologias e modelos de vigilância laboratorial, orientando protocolos clínicos para tratamento e avaliando tendências epidemiológicas.

No âmbito da saúde animal se pretende a implementação de programa de vigilância da resistência aos antimicrobianos em bactérias isoladas de frangos de corte em granjas, na indústria de produtos de 
origem animal e na indústria da alimentação animal, criando-se uma rede nacional de laboratórios agropecuários para o monitoramento da qualidade de antimicrobianos de uso veterinário e resíduos de antimicrobianos em alimentos disponíveis no comércio. Além disso, o PAN-BR determinou a implantação do BRGLASS (Brazilian Global Antimicrobial Resistance Surveillance System) para desenvolver a gestão e a interoperabilidade entre os sistemas de informação do Ministério da Saúde com o sistema nacional de monitoramento da AMR com os de Organismos Internacionais.

\section{Pontos de corte epidemiológico}

A determinação dos pontos epidemiológicos de maior importância para atuação imediata, segundo Guia de Vigilância Epidemiológica publicado pela Fundação Nacional de Saúde (FUNASA) em 2002, se dão a partir da definição de perfis epidemiológico locais, o que se faz mediante levantamento das principais infecções tratadas nos hospitais quanto a sua etiologia, sítio e populações específicas, devendo ser estratificado por setores de internação. Sendo que para a AMR este levantamento tem como apoio a Comissão de Controle de Infecção Hospitalar (CCIH) e o Serviço de Arquivo Médico e Estatístico (SAME) através dos registros de pacientes nos últimos anos. Assim a Agência Nacional de Vigilância Sanitária (ANVISA), em conjunto com a Gerência de Vigilância e Monitoramento em Serviços de Saúde (GVIMS) e Gerência Geral de Tecnologia em Serviços de Saúde, elaborou em 2017 a Diretriz Nacional para Elaboração de Programa de Gerenciamento do Uso de Antimicrobianos em Serviço de Saúde determinando que os serviços de saúde devam elaborar ou adaptar seus próprios protocolos, de acordo com as características clínicas e com os perfis epidemiológico e microbiológico locais, ressaltando que é necessário que os protocolos sejam objetivos, para que na prática clínica seu uso seja simples e rápido, e que incorporem o perfil microbiológico do setor no qual serão usados, sendo atualizados periodicamente. $\mathrm{O}$ uso de protocolos permite reduzir diferenças de condutas entre os profissionais aumentando a qualidade e a segurança da assistência médica (Faria et al., 2008).

\section{Adoção de medidas higiênico sanitárias}

Condutas e procedimentos para prevenir o desenvolvimento de infecções através de medidas higiênico sanitárias e de saneamento, como limpeza adequada e constante de ambientes hospitalares, lavagem constante de mãos, desinfecção de materiais utilizados em animais com possíveis bactérias resistentes e treinamento de equipe para reconhecer riscos de transmissão de bactérias multirresistentes, são essências no combate a AMR. Dessa forma, em locais com grande chance de transmissão e desenvolvimento de microrganismos resistentes, é importante a criação de protocolos de higiene bem definidos, como, por exemplo, o elaborado por Motta et al. (2012) e utilizado no Hospital Universitário de Juiz de Fora, segundo padrões determinados pela $\mathrm{CCIH}$, os quais devem ser seguidos pelos profissionais da saúde.

\section{Diminuição do uso da terapia empírica}

A prescrição de medicamentos de forma empírica por parte dos profissionais da saúde precisa diminuir. Muitos antibióticos de segunda e terceira geração são prescritos para terapia empírica, sem se constatar que medicamentos de primeira e segunda escolha seriam eficazes. Conforme (Hillier et al., 2014), o tratamento não deve ser iniciado até que os resultados de culturas e sensibilidade estejam disponíveis. No entanto, se for necessário o início do tratamento, a escolha do antibiótico deve ser baseada no histórico do paciente, sinais clínicos, local de infecção, associando assim os possíveis microrganismos que possam estar presentes no foco, além disso, se for viável uma citologia pode auxiliar na escolha do antibiótico. Contudo, quando os resultados da cultura estiverem prontos, os profissionais devem adequar à terapia (Leekha et al., 2011).

Utilizando dados de Hopman et al. (2019), antibióticos de segunda escolha, como aminopenicilina e cefalosporinas, foram mais utilizados entre 2012 e 2013, representando 46\% do total. Já em 2014, os mais usados foram antibióticos de primeira escolha, como tetraciclinas e sulfonamidas, correspondendo $50 \%$ do total (Figuras 1 e 2). O antibiótico mais escolhido durante os três anos foi amoxicilina com ou sem ácido clavulânico. Em 2012, o segundo maior grupo consistiu em cefalosporinas de terceira geração (cefovecina), já em 2013 e 2014 o segundo maior grupo consistiu em trimetoprim e sulfonamidas. Em relação aos antibióticos de terceira escolha, como fluoroquinolonas e cefalosporinas de $3^{\text {a }}$ geração, o 
uso diminuiu entre os anos de 2012 e 2014, no entanto, ainda representou 7,7\% do total em 2014. Com base nesses dados, deve-se destacar a importância da elaboração de diretrizes a respeito do uso de antibióticos, objetivando diminuir o uso desnecessário de antibióticos de segunda e terceira escolha.

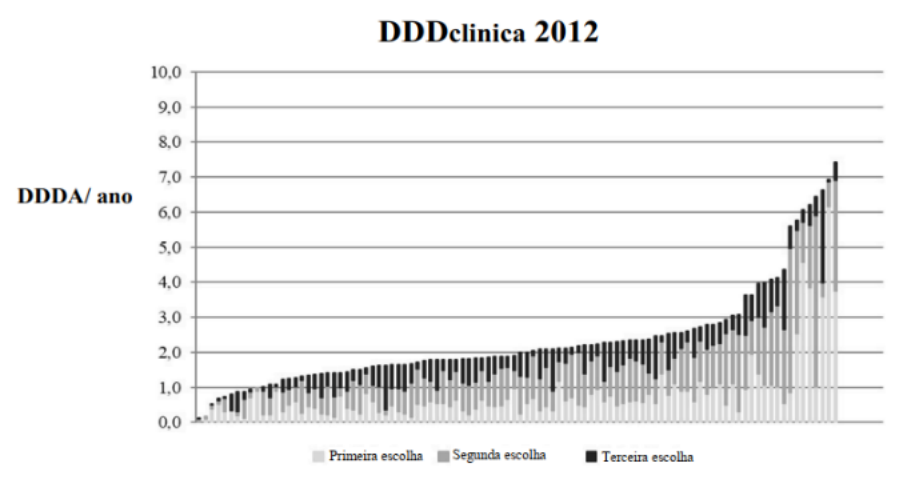

Figura 1. Dados da utilização de antimicrobianos de primeira, segunda e terceira escolha em 100 clínicas no ano de 2012 Adaptado de Hopman et al. (2019).

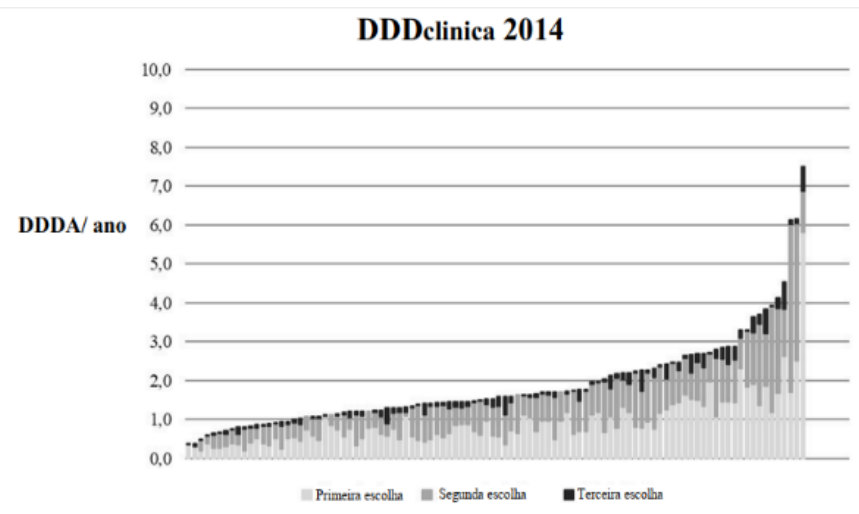

Figura 2. Dados da utilização de antimicrobianos de primeira, segunda e terceira escolha em 100 clínicas no ano de 2014 de Hopman et al. (2019).

\section{Regulamentação na venda de antibióticos}

No Brasil a venda de antibiótico direcionado para o uso humano é controlado por receita médica (Nascimento Júnior et al., 2016). No entanto, medicamentos usados na veterinária são muitas das vezes vendidos sem receita em agropecuárias, como mostrados no estudo de Leite et al. (2006) em que foram visitados 26 estabelecimentos de Curitiba em 2002, do quais $100 \%$ apresentaram prescrição de medicação por atendentes não habilitados profissionalmente. Segundo Guardabassi et al. (2018) em países da União Europeia, qualquer medicamento veterinário para uso sistêmico só pode ser obtido mediante receita e nos Estados Unidos, a partir do dia 1 de janeiro de 2017, o uso de antimicrobianos de importância médica na alimentação ou na água de animais para alimentação passou a requerer autorização veterinária.

\section{Restrição do uso de antibióticos como promotores de crescimento}

Muitos antibióticos em doses sub terapêuticas são utilizados em animais saudáveis, agindo como promotores de crescimento. De acordo com a Organização Mundial de Saúde, esse uso deve ser banido, principalmente aqueles utilizados na medicina humana, já que a utilização desses podem comprometer a eficácia e gerar aumento de resistência.

Utilizando dados de Guardabassi et al. (2018), na Dinamarca a proibição do uso de promotores de crescimento diminuiu o consumo geral de mais de 200 toneladas em 1994 para cerca de 120 toneladas em 2015 de antibióticos, apesar de terem sido necessárias mudanças de manejo, a produção de suínos não teve alterações significativas. No Brasil, foi publicado no diário da união, na portaria de número 171, no dia 13 de dezembro de 2018, a proibição de uso de antimicrobianos, como tilosina, lincomicina, 
virginiamicina, bacitracina e tiamulina, com a finalidade de melhorar o desempenho dos animais produtores de alimentos.

Pesquisas comerciais mostram que produtores brasileiros, principalmente no setor avícola, vêm se preocupando com a pressão do consumidor europeu em relação à qualidade do alimento e não utilização de promotores de crescimento, optando por alterações de manejo para atender as restrições do mercado internacional (Dörr, 2003). No entanto o banimento completo de antibióticos como promotores de crescimento em animais ainda encontra resistência por parte de produtores que veem a produtividade atrelada ao uso desses medicamentos (Valentim et al., 2019).

\section{Antimicrobial Stewardship: definição e princípios}

Com a ampliação crescente da abordagem One Health (Saúde Única) a melhor forma de gerenciamento do problema de resistência antimicrobiana inclui tomar medidas para preservar a eficácia continuada dos antimicrobianos existentes, como tentar eliminar o uso inadequado, principalmente onde são usados em grandes volumes. Exemplos são: o uso de medicação em massa de animais com antimicrobianos de importância crítica para seres humanos, como cefalosporinas e fluoroquinolonas, a longo prazo, e uso de colistina, tetraciclinas e macrólidos, para promoção do crescimento de animais. Nas pessoas é essencial melhorar a prevenção de infecções, reduzir a prescrição inadequada e o uso excessivo de antimicrobianos, de forma que se controle a disseminação das bactérias resistentes ao melhorar a higiene e o controle de infecções. Água potável e saneamento são aspectos essenciais na AMR, na qual a poluição e tratamento inadequado de resíduos industriais, residenciais e agrícolas está expandindo a resistência no ambiente (Collignon \& McEwen, 2019).

Vários países já incluíram uma abordagem de Saúde Única dentro de seus planos de ação para enfrentar a AMR, assim, no sentido de responsabilidade multisetorial e multicausal, observando a relação ser humano, animal e ambiente. A American Veterinary Medical Association (AVMA) definiu o conceito de "Antimicrobial Stewardship" no âmbito da medicina veterinária como "ações individuais adotadas pelos veterinários para preservar a eficácia e disponibilidade de medicamentos pela supervisão consciente e tomada de decisão médica responsável", que apresenta três objetivos básicos para sua aplicação: 1) manejo adequado para prevenir doenças comuns; 2) abordagem baseada em evidências para tomada de decisão; 3) usar antimicrobianos de maneira criteriosa, moderada e com avaliação contínua dos resultados da terapia (FDA, 2015).

Segundo Drew (2009), as intervenções que visam a redução da prescrição excessiva foram associadas com redução de infecções por $C$. difficile e colonização ou infecção com bactérias Gram-negativas aminoglycoside ou cefalosporina-resistente, além de as intervenções destinadas a aumentar a prescrição efetiva também ter sido capaz de melhorar o resultado clínico. Todavia, a introdução de guias à base de consenso, desenvolvidas por grupo de peritos multidisciplinar, para uso antimicrobiano no tratamento de meningite na Holanda, em 1997, mostrou em estudo retrospectivo que apenas um terço dos pacientes tinham sido tratados de acordo com as diretrizes, especulando-se que a baixa adesão a desconfiança, preferência por diretrizes desenvolvidas localmente, má divulgação e falta de incentivos para implementação. Reafirmando a necessidade de maior planejamento e alocação de recursos suficientes para divulgação e implementação efetiva dos princípios de educar e desenvolver conhecimento acerca da resistência antimicrobiana.

A grande maioria das classes antimicrobianas é usada em humanos e animais (incluindo aquicultura). Apenas poucas classes antimicrobianas são reservadas exclusivamente para humanos, assim, temos os medicamentos classificados segundo sua prioridade de uso na Figura 3, em que na primeira escolha estão os utilizados para terapia empírica, como tetraciclinas, nitroimidazóis, penicilinas de espectro estreito, trimetoprim, sulfonamidas. Os antibióticos de segunda escolha são indicados em infecções com risco de resistência, como aminopenicilina, cefalosporinas de $1^{\circ}$ geração e aminoglicolídeos. E antibióticos de terceira escolha com prioridade máxima para utilização em humanos, são os com restrita utilização quando realizados testes de cultura e susceptibilidade, como fluorquinolonas e cefalosporinas de $3^{\circ}$ e $4^{\circ}$ geração. Ressaltamos que a cada 2 anos a WHO (World Health Organization) libera nova edição sobre a prioridade de escolha de medicamentos, sendo necessário a atualização constante do profissional de saúde para acompanhar as modificações necessárias ao combate eficaz da resistência antimicrobiana (WHO, 2018). 


\begin{tabular}{|c|c|c|c|}
\hline MÁXIMA PRIORIDADE & GRANDE PRIORIDADE & MUITO IMPORTANTE & IMPORTANTE \\
\hline $\begin{array}{l}\text {.Cefalosporinas }\left(3^{\mathrm{a}}, 4^{\mathrm{a}} \text { e } 5^{\mathrm{a}} \text { geração }\right) \\
\text {.Glicopeptídeos } \\
\text {.Macrolídeos e Cetolídeos } \\
\text {.Polimixinas } \\
\text {.Quinolonas }\end{array}$ & $\begin{array}{l}\text { Aminoglicosídeos } \\
\text {.Ansamicinas } \\
\text {.Carbapenêmicos } \\
\text {.Glicilciclinas } \\
\text {.Lipopepitídeos } \\
\text {.Monobactâmicos } \\
\text {.Oxazolidinonas } \\
\text {.Penicilinas (naturais, aminopenicilinas e antipseudomonas) } \\
\text {.Derivados de Ácido Fosfônico } \\
\text {.Fármacos utilizados unicamente para tratar tuberculoses e } \\
\text { outras enfermidades micobacterianas }\end{array}$ & $\begin{array}{l}\text { Anfenicóis } \\
\text {.Cefalosporinas }\left(1^{\mathrm{a}} \mathrm{e} 2^{\mathrm{a}} \text { geração) } \mathrm{e}\right. \\
\text {.Cefamicinas } \\
\text {.Licosaminas } \\
\text {.Penicilinas (antiestafilococicos, } \\
\text { amidinopenicilina e de limitado espectro) } \\
\text {.Ácidos Pseudomônicos } \\
\text {.Riminofenazinas } \\
\text {.Estreptograminas } \\
\text {.Sulfonamidas, inibidores dedihidrofolato } \\
\text { redutase e combinações } \\
\text {.Sulfonas } \\
\text {.Tetraciclinas }\end{array}$ & $\begin{array}{l}\text {.Nitroimidazóis } \\
\text { Polipeptídeos Cíclicos } \\
\text {.Aminociclitoles } \\
\text {.Derivados de Nitrofurano } \\
\text {.Pleuromutilinas }\end{array}$ \\
\hline
\end{tabular}

Figura 3. Classificação de antimicrobianos segundo prioridade de gerenciamento de risco de resistência antimicrobiana para saúde humana (Adaptado de Critically Important Antimicrobials for Human Medicine - World Health Organization, WHO, 2018).

\section{Estratégias adotadas no Brasil}

No Brasil vem adotando-se medidas para prevenção e controle na ocorrência de resistência. A instrução normativa do Ministério da Agricultura, Pecuária e Abastecimento, de número 41, de 23 de outubro de 2017, tem como objetivo instituir o programa nacional de prevenção e controle de Resistência aos Antimicrobianos na Agropecuária, sendo denominado de AgroPrevini, no qual têm em vista a prevenção, diagnóstico e controle da resistência aos antimicrobianos na agropecuária, através da abordagem de educação sanitária, estudos epidemiológicos, vigilância e monitoramento da resistência e do uso de antimicrobianos, fortalecimento de implementação de medidas de prevenção e controle de infecções e promoção do uso racional de antimicrobianos (Nascimento Júnior et al., 2016).

Ainda assim, o livro de Saúde e Política Externa publicado pelo Ministério da Saúde em 2018 indica que o posicionamento do MAPA em relação a temas de resistência antimicrobiana é cauteloso, em vista de recomendações que estejam com base científica sólida, como no caso do banimento generalizado dos aditivos melhoradores de desempenho na produção animal que, segundo os especialistas no setor, poderia aumentar o uso de antimicrobianos terapêuticos em animais e gerar riscos de inocuidade alimentar por aumento da contaminação de carcaças.

Outra medida adotada no Brasil, segundo Vasconcelos et al. (2015) refere-se as atribuições que compete a Comissão de infecção hospitalar para o controle do uso de antimicrobianos, como: estabelecer diretrizes para o desenvolvimento do programa e estratégias de atuação de controle de infecção hospitalar de um modo geral; realizar investigação epidemiológica de surtos, sempre que indicado; elaborar, rever e atualizar normas, que visem à uniformização de medidas para prevenção, controle e contenção das infecções hospitalares; planejar normas para estudos e pesquisas epidemiológicas, estabelecer programas de racionalização do uso de antimicrobianos.

A elaboração do Plano de Ação Nacional de Prevenção e Controle da Resistência aos Antimicrobianos (PAN-BR), pautado pelos princípios definidos pela OMS, FAO e OIE, destaca-se na movimentação brasileira como plano multisetorial no combate a AMR, ao agrupar as atividades já realizadas nos diferentes setores nos últimos anos e acrescentar a abordagem de Saúde Única para que se desenvolvam de forma articulada e integrada (Estrela, 2018).

\section{Considerações finais}

O uso indiscriminado de antibióticos na medicina humana e veterinária acarretou um grande problema para a saúde mundial, o surgimento de superbactérias (bactérias resistentes aos antimicrobianos utilizados hoje em dia). Portanto há uma justa necessidade de o poder público e as autoridades em saúde intervirem, de forma mais enérgica e assertiva, com estratégias e políticas públicas que tenham como objetivo minimizar a ocorrência do surgimento de novas bactérias resistentes e buscar meios para controlar e combater as já existentes, fazendo-se cumprir as instruções do Plano de Ação Global Contra a Resistência Antimicrobiana de 2015. Estratégias essas, que estão atreladas a necessidade de ajustes financeiros e elevação do investimento na área.

\section{Referências bibliográficas}

ANVISA. (2017). - Agência Nacional de Vigilância Sanitária. Diretriz Nacional para Elaboração de Programa de Gerenciamento do Uso de Antimicrobianos em Serviços de Saúde. 
ANVISA/GVIMS/GGTES, Brasília, Brasil.

Boothe, D. M. (2006). Principles of antimicrobial therapy. Veterinary Clinics: Small Animal Practice, 36(5), 1003-1047. DOI: http://dx.doi.org/10.1385/1-59259-026-8:19

Brasil. Ministério da Agricultura Pecuária e Abastecimento. Instrução normativa No 41 de 23 de outubro de 2017.

Brasil. Ministério da Agricultura Pecuária e Abastecimento. Portaria Nº171 de 13 de dezembro de 2018.

Cao, C., Qu, Y., Sun, M., Qiu, Z., Huang, X., Huai, B., Lu, Y., \& Zeng, Z. (2015). In vivo antimicrobial activity of marbofloxacin against Pasteurella multocida in a tissue cage model in calves. Frontiers in Microbiology, 6, 759. DOI: http://dx.doi.org/10.3389/fmicb.2015.00759.

Caselani, K. (2014). Resíduos de medicamentos veterinários em alimentos de origem animal. Arquivos de Ciências Veterinárias e Zoologia Da UNIPAR, 17(3), 189-197. DOI: https://doi.org/10.25110/arqvet.v17i3.2014.4944

Collignon, P. J., \& McEwen, S. A. (2019). One health-its importance in helping to better control antimicrobial resistance. Tropical Medicine and Infectious Disease, 4(1), 22. DOI: http://dx.doi.org/10.3390/tropicalmed4010022

Dörr, A. C. (2003). O posicionamento da indústria avícola frente às restrições do mercado consumidor europeu. Universidade de São Paulo. DOI: https://doi.org/10.11606/d.11.2018.tde-20181127-162142

Drew, R. H. (2009). Antimicrobial stewardship programs: how to start and steer a successful program. Journal of Managed Care Pharmacy, $15(2$ Supp A), 18-23. DOI: http://dx.doi.org/10.18553/jmcp.2009.15.s2.18

Estrela, T. S. (2018). Resistência antimicrobiana: enfoque multilateral e resposta brasileira. Assessoria de Assuntos Internacionais de Saúde, 20, 1998-2018.

Faria, H. P., Campos, K. F. C., \& Werneck, M. A. F. (2008). Protocolos de cuidados à saúde e de organização do serviço. Núcleo de Eduação e Saúde Coletiva.

FDA. (2015). Food and Drug Administration of the US, Substances used as GRAS in food. 21, CFR 184.

Fernández-Varón, E., Cárceles-García, C., Serrano-Rodríguez, J. M., \& Cárceles-Rodríguez, C. M. (2016). Pharmacokinetics (PK), pharmacodynamics (PD), and PK-PD integration of ceftiofur after a single intravenous, subcutaneous and subcutaneous-LA administration in lactating goats. BMC Veterinary Research, 12(1), 1-10. DOI: http://dx.doi.org/10.1186/s12917-016-0863-9

Fluit, A. C., \& Schmitz, F.-J. (2004). Resistance integrons and super-integrons. Clinical Microbiology and Infection, 10(4), 272-288. DOI: http:dx.doi.org/10.1111/j.1198-743X.2004.00858.X

FUNASA. (2002). - FundaçãoNacionaldeSaúde. Guia de vigilância epidemiológica (5th ed.). Volume I. FUNASA, Brasil.

Guardabassi, L., Apley, M., Olsen, J. E., Toutain, P., \& Weese, S. (2018). Optimization of antimicrobial treatment to minimize resistance selection. American Society of Microbiology, 6(3), 637-673. DOI: http://dx.doi.org/10.1128/microbiolspec.arba-0018-2017

Guardabassi, L., \& Prescott, J. F. (2015). Antimicrobial stewardship in small animal veterinary practice: from theory to practice. Veterinary Clinics: Small Animal Practice, 45(2), 361-376. DOI: http://dx.doi.org/10.1016/j.cvsm.2014.11.005

Hillier, A., Lloyd, D. H., Weese, J. S., Blondeau, J. M., Boothe, D., Breitschwerdt, E., Guardabassi, L., Papich, M. G., Rankin, S., \& Turnidge, J. D. (2014). Guidelines for the diagnosis and antimicrobial therapy of canine superficial bacterial folliculitis (A ntimicrobial G uidelines W orking G roup of the I nternational S ociety for C ompanion A nimal I nfectious D iseases). Veterinary Dermatology, 25(3), 163-e43. DOI: http://dx.doi.org/10.1111/vde.12118

Hopman, N. E. M., Van Dijk, M. A. M., Broens, E. M., Wagenaar, J. A., Heederik, D. J. J., \& Van Geijlswijk, I. M. (2019). Quantifying antimicrobial use in Dutch companion animals. Frontiers in Veterinary Science, 6, 158. DOI: http://dx.doi.otg/10.3389/fvets.2019.00158

Jolivet-Gougeon, A., \& Bonnaure-Mallet, M. (2014). Biofilms as a mechanism of bacterial resistance. Drug Discovery Today: Technologies, 11, 49-56. DOI: http://dx.doi.org/10.1016/j.ddtec.2014.02.003 
Leekha, S., Terrell, C. L., \& Edson, R. S. (2011). General principles of antimicrobial therapy. Mayo Clinic Proceedings, 86(2), 156-167. DOI: http://dx.doi.org/10.4065/mcp.2010.0639

Leite, L. C., Villanova Júnior, J. A., Cirio, S. M., Leite, S. C., Silva, A. W. C., Diniz, J. M. F., Lunelli, D., Zadorosnei, A. C. B., Souza, L. M. B., \& Weber, S. (2006). Prescrição de medicamentos veterinários por leigos: um problema ético. Revista Acadêmica Ciência Animal, 4(4), 43-47. DOI: http://dx.doi.org/10.7213/cienciaanimal.v4i4.9498

Marsh, P. D. (2004). Dental plaque as a microbial biofilm. Caries Research, 38(3), 204-211. DOI: http://dx.doi.org/10.1159/000077756

McGowan Junior, J. E. (1983). Antimicrobial resistance in hospital organisms and its relation to antibiotic use. Reviews of Infectious Diseases, 5(6), 1033-1048. DOI: http://dx.doi.org/10.1093/clinids/5.6.1033

Ministério da Saúde. (2018). Plano de Ação Nacional de Prevenção e Controle da Resistência aos Antimicrobianos no Âmbito da Saúde Única 2018-2022 (PAN-BR). Ministério da Saúde, Secretária de Vigilância em Saúde, Departamento de Vigilância das Doenças Transmissíveis, Brasília, Brasil.

Motta, E. C., Ramos, M. G., \& Souza, R. D. (2012). Manual de procedimentos e condutas para prevenção de infeções relacionadas à assistência à saúde 2012/2013. In Hospital Universitário da Universidade Federal de Juiz de Fora (pp. 32-75). Universidade Federal de Juiz de Fora.

Munita, J. M., \& Arias, C. A. (2016). Mechanisms of antibiotic resistance. Frontiers in Microbiology, 4(2), 481-511. DOI: http://dx.doi.org/10.3389/fmicb.2015.00034

Nascimento Júnior, J. M., Paganelli, M. O., Tavares, N. U. L., Soeeiro, O. M., \& Costa, K. S. (2016). Uso racional de medicamentos: fundamentação em condutas terapêuticas e nos macroprocessos da assistência farmacêutica. Brasília: OPAS/OMS, 1(1), 1-10.

Prescott, J. F. (2017). History and current use of antimicrobial drugs in veterinary medicine. American Society of Microbiology, 5(6), 1-16. DOI: http://dx.doi;org/10.1128/microbiolspec.arba-0002-2017

Rairat, T., Hsieh, C.-Y., Thongpiam, W., Sung, C.-H., \& Chou, C.-C. (2019). Temperature-dependent pharmacokinetics of florfenicol in Nile tilapia (Oreochromis niloticus) following single oral and intravenous administration. Aquaculture, 503, 483-488. DOI: http://dx.doi.org/10.1016/j.aquaculture.2018.12.081

Ramirez, M. S., \& Tolmasky, M. E. (2010). Aminoglycoside modifying enzymes. Drug Resistance Updates, 13(6), 151-171. DOI: http://dx.doi.org/10.1016/j.drup.2010.08.003

Thomas, C. M., \& Nielsen, K. M. (2005). Mechanisms of, and barriers to, horizontal gene transfer between bacteria. Nature Reviews Microbiology, 3(9), 711-721. DOI: http://dx.doi.org/10.1038/nrmicro1234

Valentim, J. K., Rodrigues, R. F. M., Bittencourt, T. M., Lima, H. J. D., \& Resende, G. A. (2019). Implicações sobre o uso de promotores de crescimento na dieta de frangos de corte. Revista Eletrônica NutriTime, 15(4), 1-9.

Vasconcelos, D. V., Oliveira, T. B., \& Araújo, L. L. N. (2015). O uso de antimicrobianos no âmbito hospitalar e as atribuições do farmacêutico na comissão de controle de infeçcão hospitalar (CCIH). Revista Eletrônica de Ciências Humanas, Saúde e Tecnologia, 4(2), 48-62. DOI: http://dx.doi.org/10.1590/S0100-40422010000300035

WHO. (2015). - World Health Organization. Global Action Plan On Antimicrobial Resistance. World Health Organization, Geneva, Suíça.

WHO. (2018). - World Health Organization. Critically Important Antimicrobials for Human Medicine. (6th revision) World Health Organization Advisory Group on Integrated Surveillance of Antimicrobial Resistence (AGISAR), Geneva, Suíça.

Wilson, D. N. (2014). Ribosome-targeting antibiotics and mechanisms of bacterial resistance. Nature Reviews Microbiology, 12(1), 35-48. DOI: http://dx.doi.org/10.1038/nrmicro3155

Recebido: 8 de abril, 2020.

Aprovado: 21 de maio, 2020

Disponivel online: 13 de agosto, 2020.

Licenciamento: Este artigo é publicado na modalidade Acesso Aberto sob a licença Creative Commons Atribuição 4.0 (CC-BY 4.0), a qual permite uso irrestrito, distribuição, reprodução em qualquer meio, desde que o autor e a fonte sejam devidamente creditados. 